\title{
Sustainable development of energy, water, and environment systems
}

\author{
Rongrong $\mathrm{Wan}^{1} \cdot$ Meng $\mathrm{Ni}^{2}$ \\ Published online: 14 March 2020 \\ (C) Springer-Verlag GmbH Germany, part of Springer Nature 2020
}

This special issue contains 10 articles selected from the 1st International Symposium on Water Resource and Environmental Management (WREM 2018), which was held in Kunming, China, from the 28th to the 29th of November 2018. WREM is an annually held conference, which covers the topics of resilient water management, aquatic restoration, habitat conservation, hydrologic modeling, the impact of climate change on water resources, non-point source pollution, the role of industry and agriculture in water management, and others.

After a meticulous peer-review process, ten (10) high scientific-level papers have been accepted for publication. They mainly concern sustainable development of energy, water, and environment systems.

The first paper is entitled "Effects of rainfall intensities on sediment loss and phosphorus enrichment ratio from typical land use type in Taihu Basin, China" (Yang et al. 2019a). In this work, field plots were established to evaluate the effects of rainfall intensities on sediment yield and phosphorus enrichment ratio (ERP) in surface runoff. The authors simulated three types of rainfall intensities for understanding the transportation from farmland via surface runoff. The findings of this study provide valuable aid to farmers on how to manage farmland effectively to prevent soil nutrient loss and reduce water eutrophication.

The second paper "Numerical simulation study of strip filling for water-preserved coal mining" (Sun et al. 2019) aims to reduce the damage to groundwater and surface water by the underground coal mine. The effects of different strip filling conditions

Responsible editor: Philippe Garrigues

Rongrong Wan

rrwan@niglas.ac.cn

Meng Ni

meng.ni@polyu.edu.hk

1 Nanjing Institute of Geography and Limnology, Chinese Academy of Sciences, Nanjing, China

2 Hong Kong Polytechnic University, Hong Kong, China on the diversion fissure zone are studied by discrete element numerical experiments. The strip filling method can effectively prevent the upward and downward fissures of the water-blocking rock group from penetrating, and can ensure that the surface water system is not affected by the underground coal mining activities.

The third paper "Multi-objective optimized scheduling model for hydro-power reservoir based on improved particle swarm optimization algorithm" (Fang and Popole 2019) aims to study the performance of the high-pressure SCR system under the conditions of low-sulfur and high-sulfur exhaust gas. And the two main engine modulation schemes of the scavenging bypass and the turbine exhaust bypass of the original engine matching with the high-pressure SCR system were also studied. It is found that both modulation scheme methods can make the exhaust performance of the original engine meet the requirements of the IMO Tier III regulations, but the scavenging bypass modulation scheme had less impact on the original engine's performance.

The fourth paper entitled "The hydropower myth" (Williams 2019) aims to contribute new directions to understanding global hydropower development, questioning commonly held assumptions that it is ubiquitously beneficial, and investigating how these assumptions are not only false, but also the circumstances which lead them to be upheld. In particular, this paper discusses how hydropower has come to be represented as a key tool for development and as a provider of clean energy while policy and development deliberately overlooks the negative social and ecological externalities associated with hydropower development.

The fifth paper entitled "Analysis of broad leaved forest carbon sinks changes and forest economics and management in China" (Zhang et al. 2019) aims to analyze changes in broad leaved forest carbon sinks and the relations between the changes and the investment in forestry fixed assets in silviculture and afforestation and management level improvement, etc. in China from 1981 to 2014. The paper establishes carbon sink estimates using the forest stock volume conversion method and analyses recent carbon sink trends of the 
dominant species of broad leaved forest which is based on 6 times inventories of China's forest resources. The results show that a significant effect has been made by the forest carbon sinks of the dominant species of broad leaved forest and investment in forestry fixed assets in silviculture and afforestation, management level improvement, etc. though with a lag of 4-7 years, and there raises a lot of discussions of various problems regarding forest carbon sinks and forest management and economic development in the paper.

The sixth paper is entitled "An empirical study on energy utilization efficiency, economic development, and sustainable management" (Pan et al. 2019). This paper analyzes the concept of the environmental Kuznets curve, taking 35 European countries as the research objects discuss the trend of energy utilization efficiency from 1990 to 2013, and then analyzes the relationship between energy efficiency and economic development. The empirical results conclude that energy efficiency and economic development showed a quadratic U-shaped relationship, indicating that the long-term energy efficiency of the country will first decline and then rise during economic activities.

The seventh paper "Combustion and emission characteristics for a marine low-speed diesel engine with high-pressure SCR system" (Zhu et al. 2019) aims to study the performance of the high-pressure SCR system under the conditions of lowsulfur and high-sulfur exhaust gas. And the two main engine modulation schemes of the scavenging bypass and the turbine exhaust bypass of the original engine matching with the highpressure SCR system were also studied. It is found that both modulation scheme methods can make the exhaust performance of the original engine meet the requirements of the IMO Tier III regulations, but the scavenging bypass modulation scheme had less impact on the original engine's performance.

The eighth paper is entitled "The influence of extensive green roofs on rainwater runoff quality: a field-scale study in southwest China" (Liu et al. 2019). In this work, the runoff quality of two field-scale extensive green roofs with common plant-media combination in southwest China has been studied. It showed that both green roofs mainly acted as pollutant sources with greater concentrations of SS, COD, and TP when compared with rainwater quality. When compared with runoff quality from the control roof, greater TP concentrations in runoff from one green roof with commercially available substrate were observed.

The ninth paper is entitled "Cross-Strait climate change and agricultural product loss" (Lin et al. 2019). This study applies Cross-Strait ICIO table with the period 2005-2017 to estimate direct and indirect losses caused by natural disasters. The estimation indicates that the value-added losses caused by natural disasters in economic sectors account for $87.4 \%$ in Mainland China and $94.6 \%$ in Taiwan of total separately.

The final paper is entitled "Environmental policy, tax, and the target of sustainable development" (Yang et al. 2019b). The main purpose of this work considered the policy effects of enterprise heterogeneity in an open economy and studied the relationship between environmental policies and sustainable development. The results show that the optimal environmental policies for sustainable development are negative in a closed economy and positive in an open economy. Because of the assumption of imperfect competition, the result of negative tax is consistent with other existing provisions. Imperfect competition distorts efficiency more than environmental policy compensates, even if firms' productivity is heterogeneous.

Acknowledgments The guest editors of this special issue are thankful to the Editor-in-Chief of Environmental Science and Pollution Control Journal, Professor Garrigues, and the publishing editor Alexandrine Cheronet for providing an opportunity to publish selected peerreviewed papers that were presented at WREM-2018. Thanks are also due to Ms. Fanny Creusot, Editorial Assistant, and the entire production team of the journal for their valuable support in bringing out this issue successfully. Last but not the least, our sincere appreciation to all the reviewers for their invaluable and critical review comments on manuscripts that were submitted for this special issue.

\section{References}

Fang R, Popole Z (2019) Multi-objective optimized scheduling model for hydropower reservoir based on improved particle swarm optimization algorithm. Environ Sci Pollut Res. https://doi.org/10.1007/ s11356-019-04434-5

Lin H-C, Chou L-C, Zhang W-H (2019) Cross-Strait climate change and agricultural product loss. Environ Sci Pollut Res. https://doi.org/10. 1007/s11356-019-05166-2

Liu R, Stanford R, Deng Y, Liu D, Liu Y, Yu S (2019) The influence of extensive green roofs on rainwater runoff quality: a field-scale study in southwest China. Environ Sci Pollut Res. https://doi.org/10.1007/ s11356-019-06151-5

Pan X-X, Chen M-L, Ying L-M, Zhang F-F (2019) An empirical study on energy utilization efficiency, economic development, and sustainable management. Environ Sci Pollut Res. https://doi.org/10.1007/ s11356-019-04787-x

Sun WB, Wang Y, Qiu HF, Ding ZW (2019) Numerical simulation study of strip filling for water-preserved coal mining. Environ Sci Pollut Res. https://doi.org/10.1007/s11356-019-05346-0

Williams JM (2019) The hydropower myth. Environ Sci Pollut Res. https://doi.org/10.1007/s11356-019-04657-6

Yang L, Yang G, Li H, Yuan S (2019a) Effects of rainfall intensities on sediment loss and phosphorus enrichment ratio from typical land use type in Taihu Basin. China Environ Sci Pollut Res. https://doi.org/ 10.1007/s11356-018-04067-0

Yang J, Chen M-L, Fu C-Y, Chen X-D (2019b) Environmental policy, tax, and the target of sustainable development. Environ Sci Pollut Res. https://doi.org/10.1007/s11356-019-05191-1

Zhang Y, Fang L, Jing P (2019) Analysis of broad leaved forest carbon sinks changes and forest economics and management in China. Environ Sci Pollut Res. https://doi.org/10.1007/s11356-01905772-0

Zhu Y, Xia C, Shreka M, Wang Z, Yuan L, Zhou S, Feng Y, Hou Q, Abdu Ahmed S (2019) Combustion and emission characteristics for a marine low-speed diesel engine with high-pressure SCR system. Environ Sci Pollut Res. https://doi.org/10.1007/s11356-01904194-2 
Publisher's note Springer Nature remains neutral with regard to jurisdictional claims in published maps and institutional affiliations.

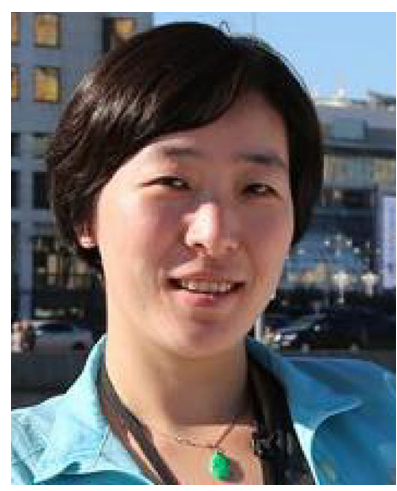

Rongrong Wan is an Associate Professor in Nanjing Institute of Geography and Limnology, Chinese Academy of Sciences. She earned her Ph.D. degree in Geography from Chinese Academy of Sciences in 2005. She joined the Environment and Society group at the Department of Geography, The Ohio State University from September 2010 to September 2011 as a visiting scholar. Her research interests include land use and land cover changes (LULCC) and their hydrological and ecological effects, assessment of watershed ecosystem services, spatially distributed watershed modeling, and spatial-temporal statistics in environment and ecology. She is teaching watershed geography in the University of Chinese Academy of Sciences and has been supervising 10 Master's students. She has obtained three grants from the National Science Foundation of China as a principal investigator. She has published 3 books/chapters, over 80 academic journal papers and conference proceedings related to geographic, ecologic, and environmental sciences.

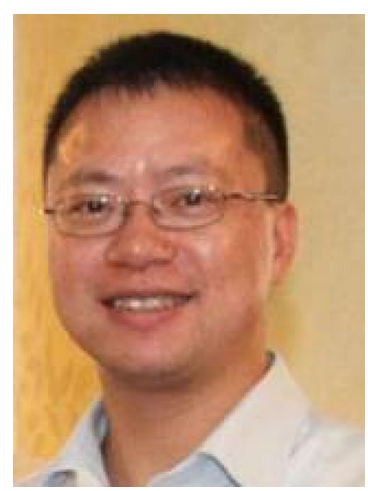

Meng Ni was born in Sichuan, China. He received his Ph.D. from the University of Hong Kong (HKU) in 2007 and received the Young Scientist Award in the same year. After working as a post-doctoral fellow at HKU, he joined The Hong Kong Polytechnic University in July 2009 as an Assistant Professor. He was promoted to an Associate Professor in July 2012 and then a Professor and Associate Head in July 2016 . Prof. $\mathrm{Ni}$ is a Humboldt Fellow and conducted collaborative research in 2017 at the Julich Research Center for 6 months. His research focuses on solid oxide fuel cells and metal-air batteries for energy conversion and storage. $\mathrm{He}$ has published over 200 papers in academic journals with SCI citations of over 9000 times. His current $\mathrm{H}$-index is 38 . Prof. $\mathrm{Ni}$ is a frequent reviewer for over 60 journals including Science and Nature Communications. He was the former Associate Editor for Science Bulletin (2015-2017). He is currently an Associate Editor for Sustainable Energy Technologies and Assessments (Elsevier). He received the Top Reviewers Award from Applied Energy in 2010 and the Best Associate Editor Awards from Science Bulletin in 2016 and 2017. 